\title{
QUINHENTOS ANOS DE BRASIL: A FRAGMENTAÇÃO DO PODER PRIVADO NAS METRÓPOLES BRASILEIRAS E O DIREITO CIVIL
}

\author{
Carlos Alberto Bittar Filho \\ Procurador do Estado de São Paulo \\ Doutor em Direito Civil pela FDUSP
}

\begin{abstract}
Resumo:
Um fenômeno característico das grandes transformações sóciojurídicas pelas quais vem passando o Brasil é a fragmentação do poder privado. Cuida-se da dissolução do poder incontrastável outrora exercido por poucos no âmbito da família, no da propriedade imobiliária, no da residência e no do trabalho.
\end{abstract}

\section{Abstract:}

One of the most characteristic phenomena of the big social and legal changes with which Brazil is being faced is the shattering of the private power. It stands for the shattering of the absolute power exercised in the past by only a few people in the fields of the family, of the estate, of the residence and of the work.

Unitermos: poder privado; poder familiar; propriedade imobiliária.

Considerando-se que o dia 22 de abril do ano 2000 foi a data em que se celebrou os quinhentos anos do Descobrimento do Brasil, é fundamental que se faça a análise de um fenômeno que está modificando a face do País nos tempos atuais e suas relações com o Direito Civil: a fragmentação do poder privado nas metrópoles brasileiras.

Por poder privado se considerará a autoridade exercida, de maneira incontrastável, no âmbito da família, da propriedade, da residência e do trabalho.'

Do ponto de vista familiar, ocorreu no cenário metropolitano brasileiro uma imensa transformação.

1. A expressão "poder privado" acha-se consagrada por Victor Nunes Leal, em sua clássica obra

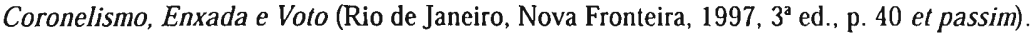


Com efeito, partiu-se de um modelo de família patriarcal, ${ }^{2}$ que foi dominante até as primeiras décadas do século e deixou impressas suas marcas no texto original do Código Civil, ${ }^{3}$ para se chegar atualmente à concepção de família nuclear.

Reduziu-se o número de pessoas que vivem na mesma casa tipicamente a pais e-filhos, desintegrando-se os antigos grupos familiares horizontalmente extensos.

Há uma tendência no sentido de que as mulheres saiam de casa, ganhando mais e mais espaço no mercado de trabalho e concorrendo de maneira sempre mais visivel com os homens, inclusive em funções antes tradicionalmente masculinas e em cargos de alta projeção social.

Em tal contexto, torna-se cada vez mais forte a luta da mulher por profissões e cargos importantes, por remunerações expressivas e reconhecimento social.

É evidente que a independência funcional e financeira da mulher traria consequiências profundas no âmbito da família.

A mais expressiva é, indubitavelmente, o maior peso de sua autoridade dentro da família, fato que conduziu à contestação da superioridade masculina nas relações domésticas.

Tão grande tem sido o impacto da luta da mulher pela igualdade que 0 legislador constitucional a consagrou expressamente no art. $5^{\circ} 1$, e no art. $226, \S 5^{\circ}$ da Constituição Federal, de 1988.

Já os filhos, em virtude dos movimentos de emancipação - muitos dos quais resultantes de influências externas -, estão tendo um papel decisivo nas relações familiares, perdendo o caráter passivo que lhes era reservado no passado.

2. Como bem explica Sérgio Buarque de Holanda (Raizes do Brasil, $26^{2}$ ed., São Paulo, Companhia das Letras, 1995.):

"Nos domínios rurais, a autoridade do proprietário de terras não sofria réplica. Tudo se fazia consoante sua vontade, muitas vezes caprichosa e despólica" (p. 80).

"Nos domínios rurais é o tipo de familia organizada segundo as normas clássicas do velho Direito Romano-Canônico, mantidas na península Ibérica através de inúmeras geraçōes, que prevalece como base e centro de toda a organização" (p. 81).

"Nesse ambiente, o pátrio poder é virtualmente ilimitado e poucos freios existem para sua tirania" (p. 82).

3. Sobre isso, veja-se Carlos Alberto Bittar Filho, Pátrio-Poder. Regime Jurídico Atual, in RT676, fevereiro de 1992, p. 80. 
Sobre o processo de modificação da família, escreveu com precisão Carlos Alberto Bittar:

Com a Revolução Industrial, na segunda metade do século XIX, o trabalho da mulher em fábricas e, posteriormente, em outras atividades econômicas deflagrou o processo crescente de desagregação familiar, acelerado com o êxodo rural que se lhe seguiu. A Revolução Tecnológica de nosso século, os movimentos de igualização da mulher e, mais recentemente, a denominada Revolução etária, com a liberação dos jovens, acabaram por conferir à idéia de família a sua visão atual, de caráter nuclear, restrita a certo número de pessoas.

Assim, a família de nossos dias é integrada apenas pelas pessoas que, com os pais, formam o grupo submetido à comunhão de vida, de domicílio e de patrimônio (pais e filhos não-casados), em especial nos grandes centros urbanos." ${ }^{4}$

Além dessas modificações radicais havidas na organização familiar, outras não menos importantes podem ser apresentadas:

a. a utilização, cada vez mais comum, da separação e do divórcio;

b. a diminuição progressiva dos matrimônios tradicionais e o aumento das uniões estáveis;

c. o crescimento do número de entidades familiares constituídas por apenas um dos pais (muitas vezes, pela mãe) e seus descendentes.

Todos esses fatores estão destruindo as bases sobre as quais se apoiava a família patriarcal, fragmentando-se a patria potestas.

Atualmente, o poder familiar, nas grandes cidades brasileiras, está mais e mais dividido entre o homem e a mulher, com a participação crescente do papel dos filhos nas decisões.

No que se refere à questão da propriedade, há que se destacar o tema da propriedade dos bens imóveis.

Sob esse aspecto, observa-se, nos centros metropolitanos, o desaparecimento dos imóveis quase-rurais que antigamente lhe caracterizavam a paisagem. Cite-se, por exemplo, a Cidade de São Paulo:

4. Novos Rumos do Direito de Família, in O Direito de Família e a Constituição de 1988, São Paulo, Saraiva, 1989, p. 3. 
Sítios e pomares de chácaras disputavam a colocação no pequeno comércio de rua em São Paulo. (...) No espaço urbano, estavam delimitados os pomares das chácaras e, precariamente abertos, terrenos devolutos e posses de roçadas volantes. Uns alimentavam quitandas e doces de sinhás donas; outros, o pequeno comércio de vinténs. ${ }^{5}$

O crescimento desordenado das metrópoles, aumentado pelo êxodo rural e pela valorização do setor terciário da economia, causou a especulação e a divisão da terra urbana.

A conseqüência desse fato é a desconcentração da propriedade da terra urbana, a qual, nos limites da cidade, está sendo detida por um número cada vez maior de pessoas.

As antigas áreas rurais das metrópoles são rapidamente compradas e divididas, de maneira que se fragmenta o poder antes exercido por poucos sobre o solo urbano (a respeito do parcelamento do solo urbano, v. a Lei Federal $\mathrm{n}$. $6.766 / 79)$.

Ademais, a reserva de valor baseada na terra urbana é hoje prática de risco, tendo-se em conta as invasões efetuadas por grupos de pessoas excluídas e também a punição legal prevista pelo princípio da função social da propriedade (Constituição Federal, arts. 170, II, e 182, §§ $2^{\circ}$ e $4^{\circ}$ ).

Ainda no âmbito residencial se pode ver a fragmentação do poder privado, em virtude da verticalização das metrópoles, do aumento populacional e da grande necessidade de espaço.

É aqui que se incluem os condomínios de apartamentos, vinculados ao regime da propriedade horizontal. ${ }^{6}$

O poder incontrastável no passado exercido pelo patriarca sobre sua própria residência perde totalmente o sentido nessa nova ordem.

Pois bem, o poder privado sobre a unidade residencial é limitado, no edifício, por normas e disposições contidas na Convenção do Condomínio e no Regulamento Interno (Lei Federal n. 4.591/64, art. $9^{\circ}$ ).

5. Maria Odila Leite da Silva Dias, Quotidiano e Poder em São Paulo no Século XIX, $2^{\text {a }}$ ed., São Paulo, Brasiliense, 1995, p. 237.

6. Caio Mário da Silva Pereira, Instituições de Direito Civil, Rio, Forense, 1970, v. IV, p. 143. 
O exercício do poder, no condomínio, é fracionado entre:

a. o síndico - responsável pela administração interna da edificação, no que tange à vigilância, à moralidade e à segurança, como também aos serviços que interessam a todos os habitantes, podendo mesmo ser pessoa física ou jurídica estranha ao condomínio (Lei Federal n. 4.591/64, art. 22, $\S 1^{\circ}$ b, e $\S 4^{\circ}$ ) -;

b. subsíndicos - cuja eleição poderá ser prevista pela Convenção (Lei n. $4.591 / 64$, art. $\left.22, \S 6^{\circ}\right)-$;

c. Conselho Consultivo - o qual é o órgão consultivo do síndico, ajudando-o na solução dos problemas que se refiram ao condomínio (Lei n. 4.591/64, art. 23) -;

d. Assembléia dos Condôminos - órgão de caráter deliberativo, no qual os votos são proporcionais, em geral, às frações ideais do terreno e partes comuns (Lei n. 4.591/64, art. $24, \S 3^{\circ}$ ).

Do ponto de vista das atividades profissionais, visivel é a fragmentação do poder privado, a qual se manifesta de duas maneiras:

a. por meio da multiplicação dos contratos de trabalho - que são caracterizados pelo poder de direção do empregador (composto pelo poder de organização da atividade, pelo poder de controle das tarefas dos empregados e pelo poder disciplinar, em conformidade com Amauri Mascaro Nascimento) ${ }^{7}$-;

b. por meio do aumento das sociedades civis e comerciais (principalmente as anônimas e as de responsabilidade limitada). ${ }^{8}$

Tais fenômenos estão associados às mudanças pelas quais as metrópoles brasileiras estão passando, de centros industriais a centros de prestação de serviços.

7. Iniciação ao Direito do Trabalho, $9^{2}$ ed., São Paulo, Ltr, 1983, pp. 128-131.

8. Francisco José de Oliveira Vianna, História Social da Economia Capitalista no Brasil, Belo Horizonte: Itatiaia; Rio: Universidade Federal Fluminense, 1987, v. 1, pp. 239-240. 
Nessas cidades, simplesmente desapareceram as primitivas organizações economicamente fechadas, dedicadas às atividades agropecuárias e artesanais, ou oikos. ${ }^{9}$

Com relação ao poder dentro da sociedade comercial, pode haver sociedades limitadas organizadas de maneira simples ou mais sofisticadas, que adotem, por exemplo, órgã̃os semelhantes aos existentes nas sociedades anônimas. ${ }^{10}$

No que diz respeito às sociedades anônimas, o poder está dividido entre os seguintes órgãos (Lei Federal n. 6.404/76, arts. 121 e ss.):

a. Assembléia Geral (deliberativa);

b. Conselho de Administração (colegiado);

c. Diretoria (representação da companhia);

d. Conselho Fiscal.

É mister não-olvidar que, nas sociedades anônimas, há o fenômeno da separação entre a propriedade das ações, que representam o capital social, e o poder de direção ou, na expressão inglesa, the splitting of the property atom. ${ }^{11}$

São Paulo, junho de 2000.

Bibliografia

BITTAR, Carlos Alberto. Novos Rumos do Direito de Família. In: O Direito de Família e a Constituição de 1988. São Paulo: Saraiva, 1989.

BITTAR FILHO, Carlos Alberto. Pátrio Poder. Regime Jurídico Atual. In: RT 676, fevereiro de 1992, pp. 79-84.

DIAS, Maria Odila Leite da Silva. Quotidiano e Poder em São Paulo no Século XIX. $2^{a}$ ed., São Paulo: Brasiliense, 1995.

HOLANDA, Sérgio Buarque de. Raizes do Brasil. $26^{a}$ ed. São Paulo: Brasiliense, 1995.

9. Francisco José de Oliveira Vianna, ibidem, pp. 133-149.

10. Rubens Requião, Curso de Direito Comercial, São Paulo, Saraiva, 1985, v. 1, pp. 334-335 e 361.

11. Francisco José de Oliveira Vianna, ibidem, p. 80. 
LEAL, Victor Nunes. Coronelismo, Enxada e Voto. $3^{\mathrm{a}}$ ed. Rio de Janeiro: Nova Fronteira, 1997.

NASCIMENTO, Amauri Mascaro. Iniciação ao Direito do Trabalho. $9^{a}$ ed. São Paulo: Ltr, 1983.

PEREIRA, Caio Mário da Silva. Instituições de Direito Civil. Rio: Forense, v. IV. 1970.

REQUIÃO, Rubens. Curso de Direito Comercial. São Paulo: Saraiva, v. I, 1985.

VIANNA, Francisco José de Oliveira. História Social da Economia Capitalista no Brasil. Belo Horizonte: Itatiaia; Rio: Universidade Federal Fluminense, v. I, 1987. 



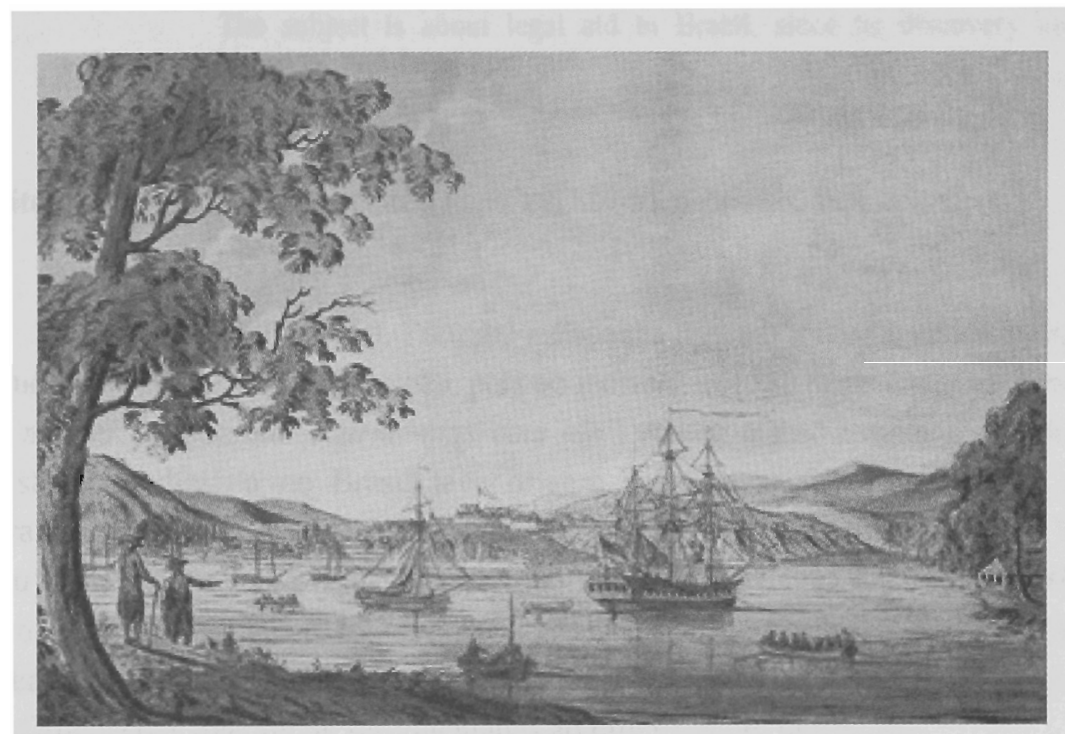

Caravelas portuguesas aportam em terras brasileiras 